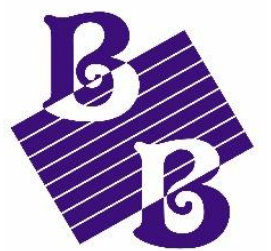

BioBacta
Journal of Bioscience and Applied Research

www.jbaar.org

\title{
Biochemical screening of low energy Infrared laser beam irradiation effect on the liver and kidney function in male albino mice
}

\author{
Moustafa Hussein Moustafa* \\ "Biophysics Department, Medical research institute, Alexandria University Egypt
}

DOI: 10.21608/jbaar.2020.134935

\begin{abstract}
Herein we conduct biochemical screening of the low energy Infrared laser beam effect (frequency: 3 and $7 \mathrm{kHz}$ ) on the liver and kidney of male albino mice as complementary investigation effect therapeutic ultrasound. The histopathological examination of organ tissues revealed a homogenous normal structure. Hematological investigation of complete blood count (CBC) was carried out and platelet count showed a significant $(\mathrm{p}<0.05)$ decline in irradiated sample tissues relative to control. Tissue-specific blood enzymes (aspartate aminotransferase (SGOT), serum creatinine, and blood urea) were still around normal levels. The rate of oxidative stress in blood as glutathione reductase (GR), and total antioxidant capacity (TCA) were estimated. Malondialdehyde (MDA) as lipid peroxidation indicator was determined as well. Conclusively, we may conclude that low energy I.R. laser has no aberrant harmful effect on the liver and kidney of male albino mice under the current experimental conditions.
\end{abstract}

Keywords: Non-ionizing radiation, infrared, low frequency, liver, kidney.

Received: September 5, 2020. Accepted: November 21, 2020. Published: December 9, 2020

\section{Introduction}

Beyond the era of x-rays discovery by Roentgen, radiation exposure was noticed in unaware radiation workers. Skin injury was predominant. After nearly a decade the first cancers attributed to radiation were registered. ${ }^{1}$

Radiation Biological effect can be ionizing or nonionizing. Non-Ionizing radiations (NI.R.) have sufficient energy only for excitation rather than realizing charged ions like ionizing ones. (NI.R.) spectrum can be sorted into main two regions, electromagnetic fields, and optical regions. The optical can be further sub-divided into ultraviolet, visible, and infra-red. The electromagnetic fields are further divided into a radiofrequency, microwave, very high frequency, and low-frequency radio wave ${ }^{2}$.

Monochromaticity, pulsed or continuous emission, collimation, and directionality all of these are all interesting properties that made laser light highly applicable in low-intensity medical therapeutics. The low-intensity infrared laser can be 
applied in inflammatory diseases4, pain management, such as cell apoptosis, cancer treatment 1 , bone regeneration ${ }^{2}$, diathermy ${ }^{3}$.

Following low-intensity laser irradiation; blood rheological and chemical properties can be modulated (like red blood cells (RBCs) deformability, aggregation, viscosity, some plasma proteins) depending on the dose and duration of exposure. $^{3}$ Laser bio radiation is based on the excitation of a chromophore in bio tissues that absorb visible or interferes with wavelengths ${ }^{45}$. As result, the radiation biological effect can be monitored.

Moreover, Laser irradiation can induce liberation of oxygen and nitrogen reactive species known as free radicals within the cells 7 . These radicals have unpaired electrons that are making them highly reactive species 8 . Unbalance between production and elimination of these reactive species creates a state known as oxidative stress9. A mammalian antioxidant mechanism is the first line to counteract these reactive species.

Superoxide dismutase and glutathione peroxidase are enzymatic examples of antioxidants, while Glutathione peptide and vitamin $\mathrm{C}$ are nonenzymatic electron receptor antioxidant10. Malondialdehyde is the major indicator of lipids peroxidation rate. A lot of risk factors, including alcohol, drugs, environmental pollutants, and irradiation, may induce oxidative stress in the liver, which in turn results in severe liver diseases ${ }^{11}$.

Until yet Laser radiobiological basis is still controversial. So that clinical protocols, based upon continuous or pulsed mode at different frequencies are recommended instructive outline in medical therapeutic applications.Error! Bookmark not defined. Herein, In the current study, the effect of low energy Infrared laser beam irradiation on the liver and kidney function of male albino mice will be studied.

\section{$\underline{\text { Material and methods }}$}

\section{Laser unit}

An Infrared diode laser model LAS 50- Hi-Tech fysiomed, Germany was used. It operated at a wavelength of $904 \mathrm{~nm}$ and peak power of $50 \mathrm{~W}$ at a frequency up to $7000 \mathrm{~Hz}$.

\section{Spectrophotometer}

The spectrophotometric assay was conducted using a spectrophotometer (Hitachi 911) automated analyzer using (In vitro Diagnostics $\AA^{\circledR}$ kits, Egypt).all procedures were according to the manufacturer's specifications.

\section{Experimental design}

All handling procedures and sample collecting were obeying the institutional animal policy protocol. The sample size for mice was chosen to be 30 albino mice that are divided into groups: Group I; ten mice non radiated act as a control group. Group II: twenty mice divided into two subgroups as ten mice exposed to Infra-Red (I.R. Laser $(4 \mathrm{kHz})$, for ten minutes. The other ten mice were exposed to I.R. Laser $(7 \mathrm{kHz})$ for ten minutes.

\section{Histopathological Examination}

Small pieces of freshly excised organs of (liver, and kidney) of all the experimental groups were processed and examined by Hematoxylin and Eosin (H\&E) method as follows: The small pieces of organs were fixed at $10 \%$ formaldehyde. Dehydration in ascending grades using alcohol was performed. Paraffin blocks were performed embedded in paraffin. Then Clean with xylene followed by rehydration in descending grades of alcohol. Stain the samples with Haematoxlin and Eosin stain, then Cleaned again with ethylene. Finally, the slides were prepared to be examined by light microscopy.

\section{Haematological and serological study}

The protocol of blood collection for hematological studies was quoted from M Salahudd et a12. Blood samples were collected by sacrificing the mice. The 
mice were kept fasting overnight, then placed in an airtight container one by one containing cotton soaked in chloroform. The abdominal and thoracic cavities were opened and the blood was collected by a syringe dI.R.ectly from the heart. The collected blood was divided into three portions.

About two (ml) blood was taken in an evacuated EDTA-containing tube for hematological studies on the same day. The remaining blood was used for the collection in a plain tube for serological studies. The serum was separated and centrifuged to remove unwanted blood cells where necessary. The samples were stored at $-20^{\circ} \mathrm{C}$ for further use of serological and biochemical determination

\section{$\underline{\text { Biochemical and serological study }}$}

Serum Aspartate Transaminase (AST) and Alanine Transaminase (ALT)

Added $2.0 \mathrm{ml}$ of serum to $1.0 \mathrm{ml}$ of a buffered substrate $(100 \mathrm{mM}$ phosphate buffer and $2 \mathrm{mM}$ alphaoxoglutarate with $100 \mathrm{mM} \mathrm{L}$-aspartate included for AST or $200 \mathrm{mM}$ DL-alanine for ALT). Dissolved 15g K2HPO4, 2.0g KH2PO4, and $300 \mathrm{mg}$ alpha oxoglutarate in $700-800 \mathrm{ml}$ of water and (a) for AST added $15.7 \mathrm{~g} \mathrm{~L}$-Aspartate, monosodium salt or (b) for ALT added 17.8g DL alanine. In both cases, the $\mathrm{pH}$ was adjusted to 7.4 with sodium hydroxide, mixed, and incubated for $60 \mathrm{~min}$ for AST or $30 \mathrm{~min}$ for ALT at $37^{\circ} \mathrm{C}$.

Then add $1.0 \mathrm{ml}$ of DNPH $(1 \mathrm{mM}$ in $1 \mathrm{M} \mathrm{HCl})$, allowed to stand at room temperature for $20 \mathrm{~min}$. Added $10 \mathrm{ml}$ of $400 \mathrm{mM}$ sodium hydroxide solution, mixed and after $5 \mathrm{~min}$, read at $500-550 \mathrm{~nm}$. For the blank take $0.2 \mathrm{ml}$ of serum, $1.0 \mathrm{ml}$ of buffer substrate, and $1.0 \mathrm{ml}$ of DNPH, mixed and completed as for test. A set of pyruvate standards $(10-100 \mu \mathrm{g})$ was run similarly and plotted the absorbance against concentration.

\section{$\underline{\text { Serum creatinine and blood Urea level }}$}

Creatinine in alkaline solution forms a yellow-red complex with alkaline picrate in Kinetic colorimetric method (Fixed rate) Jaffé reaction without deproteinization. Urea is hydrolyzed by urease to form ammonium and carbonate. In an alkaline medium, the ammonium ions react with the salicylate and hypochlorite to form a green-colored indophenol (2.2 dicarboxylindophenol). The working procedure was followed according to determination kits (Vitro Scient).

\section{serum Malondialdehyde (MDA)}

The procedure was adopted from Deepa D'souza et alError! Bookmark not defined. as follow; $2 \mathrm{~mL}$ of blood was collected. The serum was separated by centrifuging the blood sample at $3000 \mathrm{rpm}$ for $5 \mathrm{~min}$. $100 \mu \mathrm{L}$ serum is diluted to $500 \mu \mathrm{L}$ with distilled water. The samples are kept in a boiling water bath for $15 \mathrm{~min}$. To the diluted sample $1 \mathrm{~mL}$ of Trichloroacetic acid -2-thiobarbituric acid-HCl reagent is added. The reaction mixture is cooled and centrifuged. The supernatant is taken and the optical density of the pink color formed is read at $535 \mathrm{~nm}$. The optical density of the pink color formed is dI.R.ectly proportional to the concentration of serum MDA in the given sample. Sample concentration is calculated from the following: sample $=\mathrm{A}$ sample $\div \mathrm{A}$ standard $\times 10 \quad \mathrm{nmol} / \mathrm{ml}$

\section{Plasma total antioxidant capacity}

The determination of the total antioxidative capacity (TAC) is performed by the reaction of antioxidants in the sample with a defined amount of exogenously provide hydrogen peroxide $\left(\mathrm{H}_{2} \mathrm{O}_{2}\right)$. The antioxidants in the sample eliminate a certain amount of the provided hydrogen peroxide. The residual $\mathrm{H}_{2} \mathrm{O}_{2}$ is determined colorimetrically by an enzymatic reaction which involves the conversion of 3,5 , dichloro -2-hydroxy benzensulphonate to a colored product. Total antioxidant Sample concentration is calculated from the following = absorbance blanksample absorbance×3.33 (m M/L)

\section{Glutathione reductase}


Glutathione reductase (GR) reduces glutathione (GSSG) to GSH, which reacts with 5, 5'-dithiobis (2nitrobenzoic acid) (DTNB) to generate TNB2(yellow color, wavelength $\lambda \max =405 \mathrm{~nm}$ ) that can be determined by spectrophotometer.

Statistical analysis: The data were analyzed statistically between normal and treated values by one way ANOVA with post-hoc Duncan's multiple range test.

\section{Results}

The macroscopic photographs were captured to investigated histopathological integrity for both liver and kidney of irradiated samples relative to the control group. The photos Figure :1show no alteration in the cellular integrity for both liver and kidney epithelial cell samples.

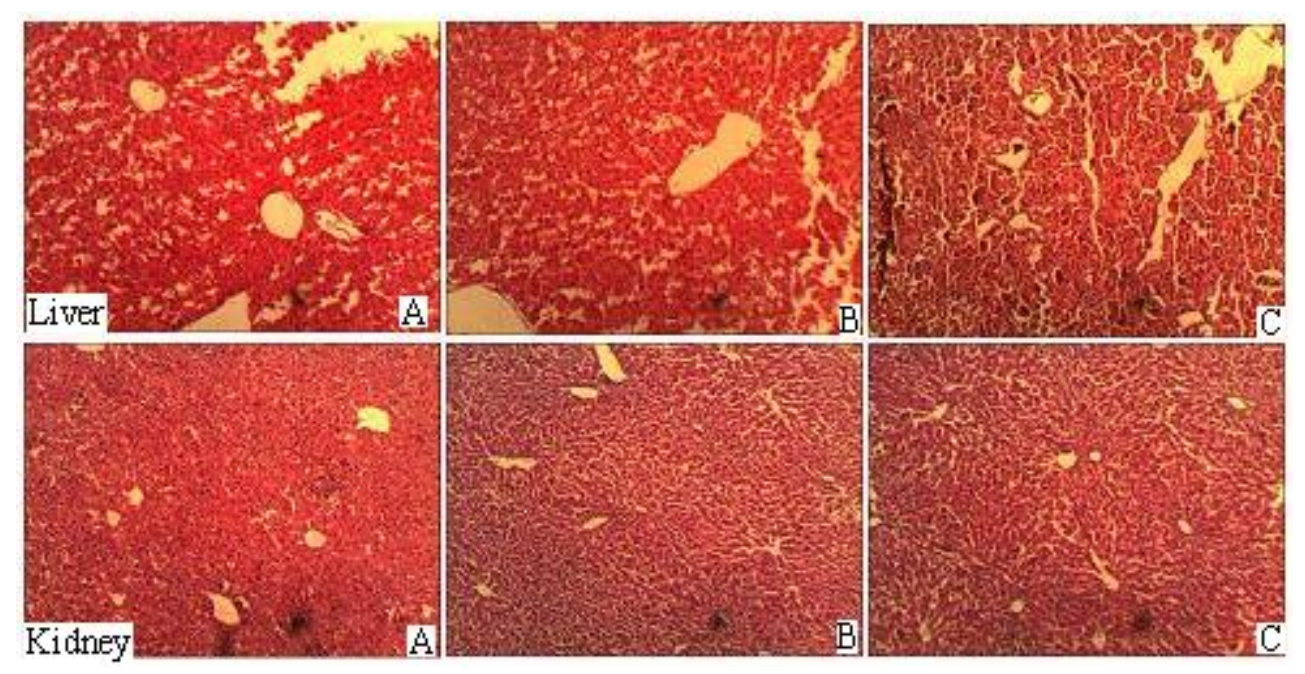

Figure :1Microscopic photographs showing morphological details of sample tissue of liver (upside) and kidney (downside) tissue, where A Control group, B, C I.R. laser I.R.radiated samples respectively.

\section{$\underline{\text { Hematological studies }}$}

Complete blood count (CBC) parameters for sample groups are tabulated in Table 1.There was no significant difference $(p<0.05)$ in values of hemoglobin (HGB), red blood cells (RBCs), and other red blood indices such as haematocrit (HCT), mean corpuscular volume (MCV), mean corpuscular hemoglobin content (MCHC) are still within normal ranges. A significant decrease in platelets and white blood cell count was noticed in I.R. 7000 irradiated group compared with a control group $(\mathrm{P}<0.05)$.

Table 1: Complete blood picture parameters (CBC) for study groups.

\begin{tabular}{|c|c|c|c|c|c|c|c|c|}
\hline & $\begin{array}{c}\mathbf{R B C} \\
(\mathbf{M} / \mu \mathrm{L})\end{array}$ & $\begin{array}{l}\text { HGB } \\
(\mathrm{g} / \mathrm{dL})\end{array}$ & $\begin{array}{c}\text { HCT } \\
(\%)\end{array}$ & $\begin{array}{c}\text { MCV } \\
\text { (fL) }\end{array}$ & $\begin{array}{c}\text { MCH } \\
\text { (pg) }\end{array}$ & $\begin{array}{c}\text { MCHC } \\
(\mathrm{g} / \mathrm{dL})\end{array}$ & $\underset{(\mathbf{m m} / \mathbf{\mu L})}{\text { PLT }}$ & $\begin{array}{c}\mathrm{WBC} \\
(\mathrm{mm} / \mu \mathrm{L})\end{array}$ \\
\hline Control & $11.4 \pm 1.8$ & $14 \pm 1.2$ & $44.6 \pm 2.4$ & $59.4 \pm 2.5$ & $18 \pm 1$ & $38 \pm 3.2$ & 671 & \\
\hline I.R. laser 4000 & $10 \pm 1.5$ & $12.6 \pm 1.2$ & 52 & $52 \pm 2.5$ & $13 \pm 0.7$ & $32 \pm 3.2$ & 369.3 & 1. \\
\hline I.R. laser 7000 & $12 \pm 0.8$ & $14 \pm 1.2$ & $\overline{59.6 \pm 2.4}$ & $\begin{array}{l}56.3 \\
\pm 2.5\end{array}$ & $16 \pm 1.3$ & $35 \pm 1.4$ & 5 & \\
\hline
\end{tabular}

F: value for ANOVA test, a: Significant with Normal group*: Statistically significant at $\mathrm{p} \leq 0$. 05 Data was expressed by using mean \pm SD. 


\section{Effects on biochemical parameters}

Liver enzymes (ALT, AST) and kidney function parameters (urea and creatinine) are represented in Figure :1.There is no significant alteration in study groups compared with a control group.

\section{$\underline{\text { Total antioxidant activity }}$}

The lipid peroxidation activity and malonaldehyde levels are shown in our study, irradiated groups with I.R.laser exhibited significantly high levels of MDA, as compared with the control group. Regarding the antioxidant capacity, all study groups showed decreased activities of antioxidants (GR, GST, and TAC) in comparison with normal animals $(\mathrm{p}>0.05)$.

Table 2: Representation of mean values for antioxidant parameters; glutathione (GST), Gluthaion reductase (GR), total antioxidant capacity (TAC), beside malondialdehyde (MDA) in comparison with a control group.

\begin{tabular}{|ccccc|}
\hline Group Name & $\begin{array}{c}\text { GST } \\
(\mathbf{U} / \mathbf{m l})\end{array}$ & $\begin{array}{c}\text { GR } \\
(\mathbf{m U} / \mathbf{m l})\end{array}$ & $\begin{array}{c}\text { TAC } \\
(\mathbf{m M} / \mathbf{L})\end{array}$ & $\begin{array}{c}\text { MDA } \\
(\mathbf{n m o l} / \mathbf{m l})\end{array}$ \\
\hline Normal & $3.95 \pm 0.92$ & 0.082 & 0.73 & 24 \\
& & \pm 0.0 & \pm 0.0 & \pm 0.05 \\
\hline 3000 I.R. laser & $0.53^{\mathrm{a}} \pm 0.21$ & 0.022 & $0.12^{\mathrm{a}}$ & $171.55^{\mathrm{a}}$ \\
& & \pm 0.0 & \pm 0.0 & \pm 0.05 \\
\hline 7000 I.R. laser & $0.57^{\mathrm{a}} \pm 0.66$ & $0.025^{\mathrm{a}}$ & $0.25^{\mathrm{a}}$ & $144.62^{\mathrm{a}}$ \\
& & \pm 0.0 & \pm 0.0 & \pm 0.05 \\
\hline
\end{tabular}
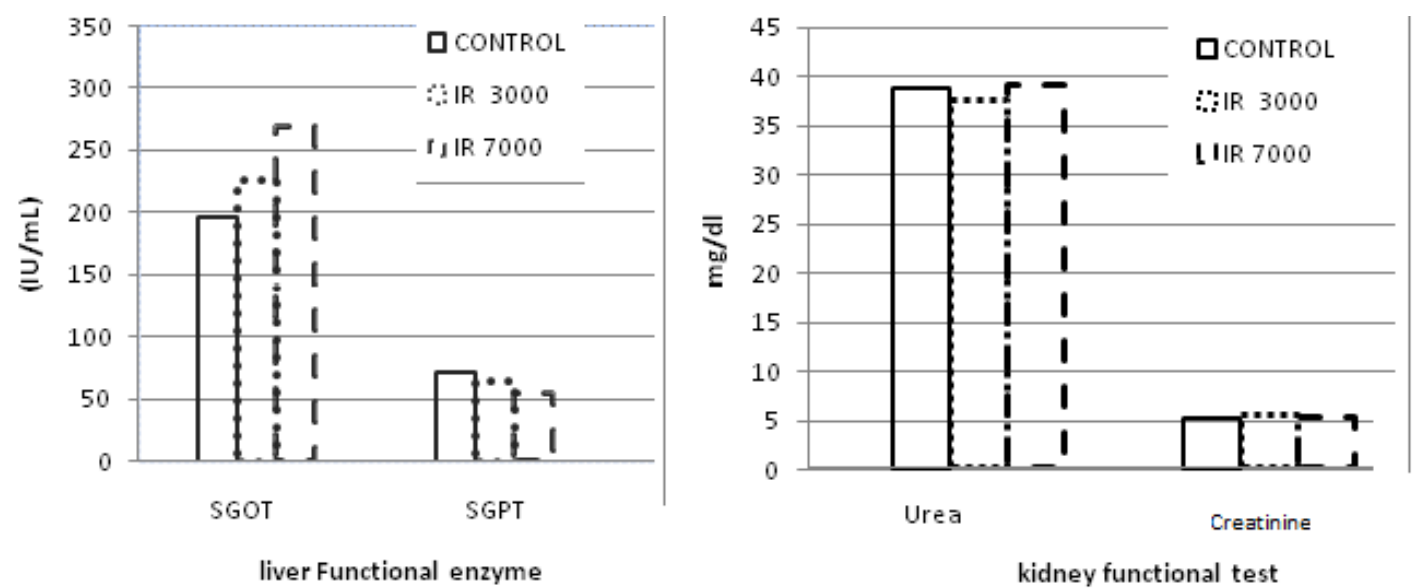

Figure 2: Graphical representation of liver enzymes (AST, ALT) at the left side and kidney functional tests (urea, creatinine) at the right side as indicators of liver and kidney physiological changes upon I.R. laser irradiation. 


\section{$\underline{\text { Discussion }}$}

Upgrading technology makes our present world a pool of electromagnetic waves irradiation2.our daily lifestyle (Cooking Home-aid tools, microwave, oven, electric heater) aids in increase the rate of exposure including industrial noising, working environment, cell phones, and computers ${ }^{1,5}$.

Laser bio radiation is based on the excitation of chromphorein biotissues that absorb visible or infrared wavelengths, as result, the bioeffect can be monitored .liver diseases are often reflected by monitoring biochemical enzymes (AST, ALT) usually reflect hepatocytes integrity or cholestasis. The main functional blood tests for kidney are waste products that filter such as urea, creatinine.

In the current study, I.R. irradiated samples show no or moderate focal hydropic degeneration, in comparison with control. The portal vein is still normal. There are no signs of necrotic changes at a cellular level. These findings are consistent with Salem $\mathrm{ES}^{14,15}$, Karu T.I. ${ }^{16}$.

Low energy laser irradiation affects tissue pathology. It affects the pathological tissues. In the current work, CBC parameters such as RBC, HGB, and HCT are slightly influenced by low frequency (I.R.3000). This finding may be due to the strong absorption of irradiation by hemoglobin, but without damaging the RBCs membranes4.

At higher laser frequency (I.R.7000), platelet count shows a significant $(\mathrm{p}<0.05)$ decrease than control, which can be reflected attenuated platelet response to activators, leading to a gradual loss of natural platelet reactivity ${ }^{6,12}$.

The antioxidant capacity was estimated as a preventive line for liver and kidney injury. Nonenzymatic antioxidants (such as GST) showed decreased activities in comparison with a control group. I.R. laser-irradiated groups were the most remarked of irradiated groups ${ }^{(12,13)}$. Cellular lipid peroxidation was evaluated by malonaldehyde (MDA) level (18). I.R. Laser I.R.radiated groups exhibited a significantly high level of MDA, as compared with the control group. This finding was coincident with the work of Luis DT et aland Errki J V. (15).

\section{Conclusion}

Following above, it has even been speculated that using An Infrared It operated at a wavelength of 904 $\mathrm{nm}$ and peak power of $50 \mathrm{~W}$ at a frequency up to 7000 $\mathrm{Hz}$ may contribute to significant alteration at cellular antioxidant activity to both irradiated liver and kidney under current experimental conditions.

\section{Acknowledgement}

I would like to appreciate the help provided by $D r$. Eslam A A Nasser, PhD laboratory specialist at Alexandria fever hospital, in sample management and animal care laboratories. Assistance provided by Dr. Ahmed A. Yameny, head of the society of pathological biochemistry and hematology, chief of medical laboratory specialists syndicate.

\section{$\underline{\text { References }}$}

1. Stone, Robert S. (1959). "EO Lawrence-A Great Physicist's Influence on Medicine." Radiology 72.1: 109-111.

2. Non-Ionizing Radiations-Sources, Biological Effects, Emissions and Exposures Kwan-Hoong Ng

3. Rajamanickam Baskar*, Jiawen Dai, Nei Wenlong, Richard Yeo, and Kheng-Wei Yeoh.Biological response of cancer cells to radiation treatment. Front Mol Biosci. 2014; 1: 24

4. Abdel-Magied N, Elkady AA, Abdel Fattah SM. Effect of Low-Level Laser on Some 
Metals Related to Redox State and Histological Alterations in the Liver and Kidney of Irradiated Rats. Biol Trace Elem Res. 2020 Apr;194(2):410-422. DOI: 10.1007/s12011-019-01779-3. Epub 2019 Jul 11. PMID: 31313245.

5. Stephen Y. Kang, et al. Parathyroid hormone reverses radiation induced hypovascularity in a murine model of distraction osteogenesis. Bone. 2013 Sep; 56(1): 9-15.

6. Modified Health Effects of Non-ionizing Electromagnetic Radiation Combined with Other Agents Reported in the Biomedical Literature Ronald N. Kostoff and Clifford G.Y. Springer International Publishing AG 2017.

7. ANTIOXIDANTS REDUCE CONSEQUENCES OF RADIATION EXPOSURE. Paul Okunieff, Steven Swarts, Peter Keng, Weimin Sun, Wei Wang, Jung Kim, Shanmin Yang, Hengshan Zhang, Chaomei Liu, Jacqueline P. Williams, Amy K. Huser, and Lurong Zhang

8. Sha Li, Hor-Yue Tan, Ning Wang, Zhang-Jin Zhang, Lixing Lao, Chi-Woon Wong, and Yibin Feng.The Role of Oxidative Stress and Antioxidants in Liver Diseases.

9. Hocking B1, Gordon I.Decreased survival for childhood leukemia in proximity to television towers. Arch EnvI.R.on Health. 2003 Sep;58(9):560-4.

10. Tomohito Sato1, Manabu Kinoshita2*, Tetsuo Yamamoto1, Masataka Ito3, Takafumi Nishida1, Masaru Takeuchi4, Daizoh Saitoh5, Shuhji Seki2, Yasuo Mukai1Treatment of I.R.radiated Mice with High-Dose Ascorbic Acid Reduced Lethality.

11. Deepa D'souza, Babu G Subhas, ShishI.R. Ram Shetty, Preethi Balan. Estimation of serum malondialdehyde in pot entially malignant disorders and postantioxidant treated patients: A biochemical study.Contemp Clin Dent. $2012 \quad$ Oct-Dec; 3(4): 448451. DOI: 10.4103/0976-237X.107438.

12. M Salahuddin, $\mathrm{H}$ Akhter, $\mathrm{S}$ Akter, MA Miah* and N Ahmad. Effects of probiotics on haematology and biochemical parameters in mice. The Bangladesh Veterinarian (2013) 30(1) : 20 - 24

13. Effects of Ultrasonic Noise on the Human Body-A Bibliographic Review Bożena Smagowska. International Journal of Occupational Safety and Ergonomics (JOSE) 2013, Vol. 19, No. 2, 195-202

14. Salem, E. $S$. Assessment of the capacity of different laser energy densities on the liver tissue repaI.R. in gamma I.R.radiated mice.

15. Erkki J. Valtonen. Influence of Ultrasonic Radiation in the Medical Therapeutic Range on the Fine Structure of the Liver Parenchymal Cell ERKKI J. V A L T O

16. Karu T.I. (2010): Multiple roles of cytochrome $\mathrm{c}$ oxidase in mammalian cells under action of red and I.R.-A radiation. IUBMB Life, 62(8):60710.

17. Effects of ultraviolet radiation, visible light, and infrared radiation on erythema and pigmentation: a review Lindsay R. Sklar, Fahad Almutawa, Henry W. Lim and Iltefat Hamzavi.

18. Dose-Response Effects of $810 \mathrm{~nm}$ Laser Light on Mouse Primary Cortical Neurons.Sulbha K. Sharma, PhD1,2, Gitika B. Kharkwal, PhD1,2, Mari Sajo, MS1,3, Ying-Ying Huang, Luis De Taboada, FSEE5, Thomas McCarthy, DVM5, and Michael R. Hamblin, 